\title{
WORK SYSTEM ANALYSIS OF POWER SUPPLY IN OPTIMIZING ELECTRICITY ON PERSONAL COMPUTER
}

\author{
Sudarmaji \\ Fakultas IImu Komputer Universitas Muhammadiyah Metro \\ Jalan Ki. Hajar Dewantara No.116 Kota Metro Lampung \\ Email: majidarma5022@gmail.com
}

\begin{abstract}
ABSTRAK
Prinsip Kerja DC Power Supply - merupakan sumber energi untuk sebuah komputer agar dapat beroperasi. Power supply mengubah arus dari AC 110 volt $60 \mathrm{~Hz}$ atau 220 volt $50 \mathrm{~Hz}$ menjadi DC $+3,3$ volt, +5 volt dan +12 volt. Power Supply harus membawa suplai listrik DC yang baik dan stabil sehingga sistem dapat berjalan dengan baik. Alat yang berjalan pada tegangan yang disuplai oleh regulator tegangan onboard, sebagai contoh RIMM dan RIMM membutuhkan 2,5 volt sedangkan AGP AX dan card membutuhkan 1,5 volt, keduanya disuplai oleh regulator onboard dari motherboard. Selain menyuplai tenaga listrik, Power Supply dapat mencegah komputer untuk mulai dijalankan sampai tegangan Power Supply ada pada daerah yang telah ditentukan. Power Good merupakan tanda tes yang khusus yang dikirim ke motherboard sebagai sinyal aktif pada komputer, biasa ditandai dengan menyala warna hijau pada saat tombol power ditekan. Arus yang dikeluarkan oleh Power Supply merupakan arus searah (DC), daya yang dikeluarkan terdiri dari 200 watt, 250 watt, 300 watt, 350 watt, 400 watt hingga 600 watt. Komputer dengan prosessor Intel Pentium 4 keatas menggunakan daya sebesar 380 watt hingga 450 watt.
\end{abstract}

Kata Kunci: Power Supply, Komputer, DC, Power Good, dan volt

\section{PENDAHULUAN}

Power Supply Unit (PSU) berfungsi untuk mengubah tegangan listrik (AC $220 / 230 / 240 \mathrm{~V}, 110 / 120 \mathrm{~V})$ agar bisa digunakan oleh komputer (DC 3,3 V, $5 \mathrm{~V}$, $12 \mathrm{~V})$. Besarnya listrik yang mampu ditangani power supply ditentukan oleh dayanya dan dihitung dengan satuan Watt. Power Supply adalah sebuah perangkat yang ada di dalam CPU yang berfungsi untuk menyalurkan arus listrik ke berbagai peralatan kom Perangkat ini memiliki 5 connector atau lebih, yang dapat disambungkan keberbagai peralatan seperti: Motherboard, Harddisk, Floppy Disk Drive, dan CD - ROM

Power supply yang berkualitas kurang baik dapat menghasilkan tegangan DC yang tidak rata dan banyak riaknya (ripple). Jika digunakan dalam jangka waktu yang cukup lama akan menyebabkan kerusakan pada komponen komputer, misalnya Harddisk. Salah satu komponen penting pada power supply adalah pendingin (cooling). Dilengkapi Konektor 24 pin ATX Beberapa motherboard memerlukan 24 pin ATX Connector. Daya pada power supply $430 \mathrm{~W}$ dan $500 \mathrm{~W}$, baik dengan 20 dan 24 pin konektor. Molex Connector Ini adalah IDE konektor yang pasokan daya ke hard drive dan cdroms. Konektor floppy The 4 pin konektor floppy pasokan daya ke floppy drive yang dapat di komputer Anda. Konektor Aux Look pada motherboard dan lihat apakah ada slot yang menerima 6 pin konektor Aux. Jika ada slot untuk itu maka kemungkinan anda akan membutuhkannya. Konektor SATA Hard drive dan perangkat lain dengan konektor sata. Jika Anda memiliki perangkat komputer dengan koneksi sata maka anda yang membutuhkan power supply dengan konektor sata. Salah satunya adalah XPower 550 Watt Power Supply. Fungsi Power Supply Pada dasarnya Fungsi utama dari power supply adalah mengubah aliran 
listrik arus bolak-balik (AC) yang tersedia dari aliran listrik (di Indonesia, PLN). Menjadi arus listrik searah (DC) yang dibutuhkan oleh komponen pada PC. Power supply termasuk dari bagian power conversion. Power conversion sendiri terdiri dari tiga macam: AC/DC Power Supply, DC/DC Converter, dan DC/AC Inverter. Power supply untuk PC sering juga disebut sebagai PSU (Power Supply Unit). PSU termasuk power conversion AC/DC.

Sebagai konversi input listrik AC menjadi DC, memberikan arus listrik / tegangan DC yang sesuai dengan yang dibutuhkan, dapat menghasilkan arus listrik DC yang lebih merata, dapat mengendalikan arus listrik / tegangan agar tetap terjaga tetapi tergantung beban daya, dan perubahan kenaikan temperature kerja juga toleransi perubahan tegangan daya input, mencegah naiknya tegangan listrik (jika terjadi).

Power Supply begitu penting peranannya sebagai penunjang hidup komputer kamu di rumah. Power supply itu ibaratnya seperti jantung ditubuh manusia.Power supply merupakan sebuah komponen untuk menyediakan dan mengalirkan arus listrik untuk komponenkomponen lainnya dalam sebuah CPU. Dari arus listrik yang ada dirumah yang dihubungkan ke power supply komputer Anda, dari power supply tersebut barulah arus listrik sebesar 220Volt ini diperkecil dan dibagi-bagi pada komponen lainnya. Rata-rata tegangan yang dihasilkan power supply antara 5-12 volt dan dipakai untuk menghidupkan komponen lain seperti harddisk, mainboard yang akan membaginya lagi kepada keyboard dan mouse serta piranti USB lainnya, cd-room. Power supply sudah menjadi satu paket dengan cassing komputer, ketika Anda membeli sebuah komputer dengan rata-rata tegangan sebesar 350 Watt. Besar tegangan tersebut sudah mencukupi untuk kebutuhan komputer saat ini (kebutuhan standar).

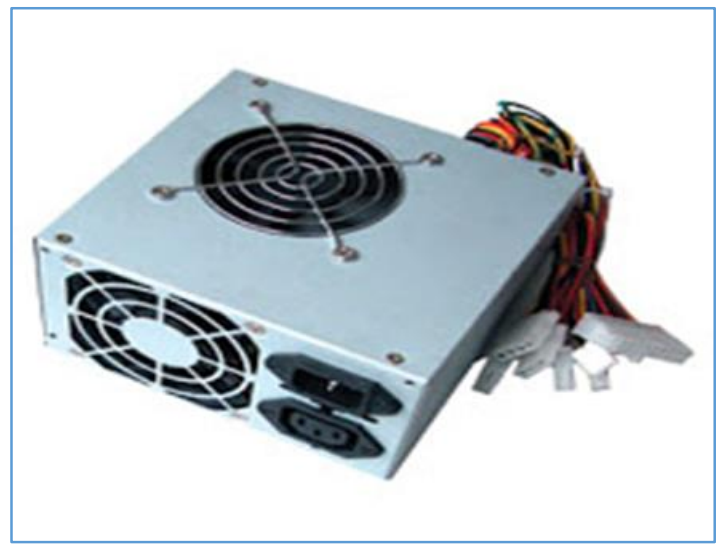

Gambar 1. Power Supply jenis AT

Pada power supply jenis AT ini, tombol ON/OFF dihubungkan langsung pada tombol casing. Untuk menghidupkan dan mematikan komuter, kita harus menekan tombol power yang ada pada bagian depan casing. Power supply jenis AT ini hanya digunakan sebatas pada era komputer pentium II. Pada era pentium III keatas atau hingga sekarang, sudah tidak ada komputer yang menggunakan Power supply jenis AT.

\section{TINJAUAN PUSTAKA}

Catu daya (power supply) berfungsi sebagai pemasok listrik dalam rangkaian komputer. Masukan komponen ini berupa arus listrik bolak-balik (AC) selanjutnya catu daya mengonversi arus bolak-balik menjadi arus searah (DC), arus searah inilah yang sesungguhnya digunakan oleh komponen-komponen dalam komputer. Catu daya dapat di hidupkan dan dimatikan melalui tombol On-Off yang terdapat di bagian depan casing komputer.



Gambar 2.Komponen Power Supply jenis ATX 
Power Supply ATX (Advanced Technology Extended) adalah jenis power supply jenis terbaru dan paling banyak digunakan saat ini. Perbedaan yang mendasar pada PSU jenis AT dan ATX yaitu pada tombol powernya, jika power supply AT menggunakan Switch dan ATX menggunakan tombol untuk mengirikan sinyal ke motherboard seperti tombol power pada keyboard.

Power Supply adalah Perangkat Komputer yang bertugas untuk memberikan daya pada setiap perangkat komputer yang lain. sekilas keberadaan power supply dalam sebuah PC hanyalah komponen tambahan, terlihat begitu banyak pembahasan di dunia maya tentang power supply masih sangat sedikit, namun jika di perhatikan secara keseluruhan sistem komputer, power supply adalah komponen yang sangat menentukan dalam kelangsungan kerja PC, karena jelas, tanpa adanya power supply yang bekerja dengan baik akan mempengaruhi kinerja hardware komputer yang lain.

Power supply juga merupakan perangkat yang berfungsi untuk mengubah arus listri dari AC ( arus Bolak balik ) ke DC ( Arus searah ), karena setiap komponen perangkat keras komputer hanya dapat menerima arus listrik DC ( bersifat searah ). Power supply dilengkapi dengan kabel arus DC dengan bermacam - macam jenis konektor yang tujuanya untuk mempermudah pendistribusian arus pada setiap komponen hardware komputer, konektor arus yang dimiliki antara lain :

1. Konektor 20/24 pin ATX Motherboard ( memberikan daya yang utama pada motherboard )

2. Konektor 4 pin peripheral power (memberikan daya pada Hardisk jenis IDE, CD-ROM dan

terkadang untuk FAN tambahan / Kipas)

3. Konektor $4 / 8$ pin $12 \mathrm{~V}$ (memberikan daya pada motherboard server)

4. Konektor 6-pin PCIe (mengalirkan arus kartu grafis jenis PCIe)
5. Konektor floppy (memberikan daya pada floppydisk drive)

6. Konektor SATA (memberikan daya untuk HardDisk dan CD-Room jenis SATA)

Power Adapter Laptop atau Power supply pada Laptop adalah sebuah perangkat yang bertujuan untuk menurunkan tegangan tinggi dari sumber listrik menjadi tegangan rendah. Selain itu Power Adapter Laptop juga bertugas untuk mengubah listrik AC menjadi DC agar dapat digunakan oleh laptop. Walaupun laptop dapat digunakan dengan power suply langsung tanpa baterei, namun sebenarnya fungsi utama power suply adalah untuk charge baterei laptop.

Power AC/DC Adapter laptop merupakan Perangkat Notebook yang biasanya didukung oleh baterai isi ulang internal yang dibebankan menggunakan catu daya eksternal, dengan output tegangan DC biasanya di kisaran 7,2-14,8 volt. Power Adapter Laptop biasanya eksternal, dan terhubung ke laptop melalui kabel konektor AC. Power supply dapat mengisi baterai dan sebagai sumber daya laptop secara bersamaan, ketika baterai terisi penuh, laptop terus berjalan pada daya yang disediakan oleh power supply eksternal. Berat Power Adapter Laptop sekitar 400 gram dan ditambahkan ke keseluruhan berat notebook. Ketika Anda membeli adaptor baru, Anda harus mengikuti aturan ini: Tegangan keluaran harus sama, amper bisa sama atau lebih tinggi dari pada adaptor asli. Jika Anda mencari adaptor baru, Anda harus memeriksa hal berikut:

1. Adaptor baru Anda harus memiliki konektor yang sama persis (socket ujung adaptor) seperti yang asli.

2. Adaptor baru Anda harus mempunyai keluaran tegangan yang sama persis dengan yang asli.

3. Polaritas pada plug adaptor baru harus sama seperti pada aslinya. Anda dapat menemukan tegangan output dan arus listrik pada label adaptor. 


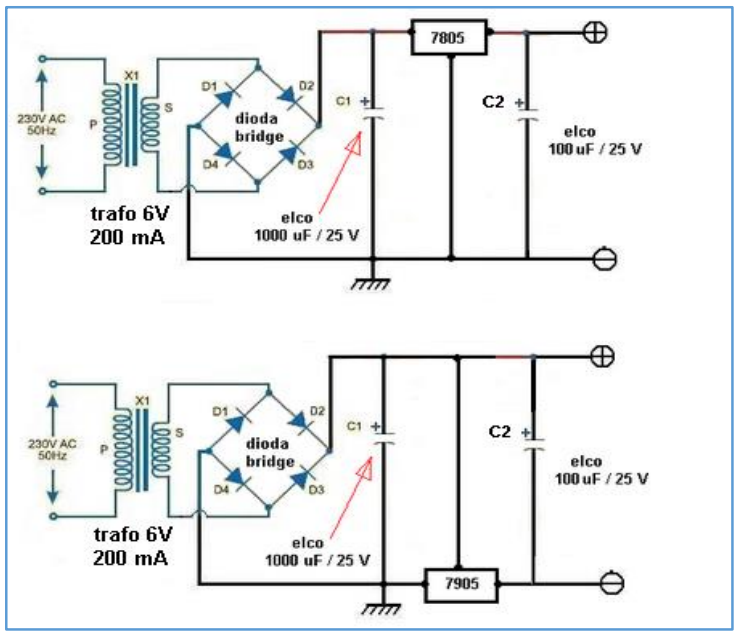

Gambar 3. Rangkaian Elektronik pada catu daya komputer

Power supply sebagai sumber daya peralatan elektronik aplikasi, memberikan banyak kelebihanan yang tidak dimiliki jenis konvensional lainnya. Selain memiliki respons yang baik dan proteksi pembebanan lebih atau hubung singkat yang sangat baik, beratnya juga sangat ringan, kestabilan tegangan keluaran yang sangat baik, dan jangkauan variasi catu tegangan masukan yang lebar. Perancangan power supply berdasarkan rangkaian elektronik dapat dilihat pada gambar3.

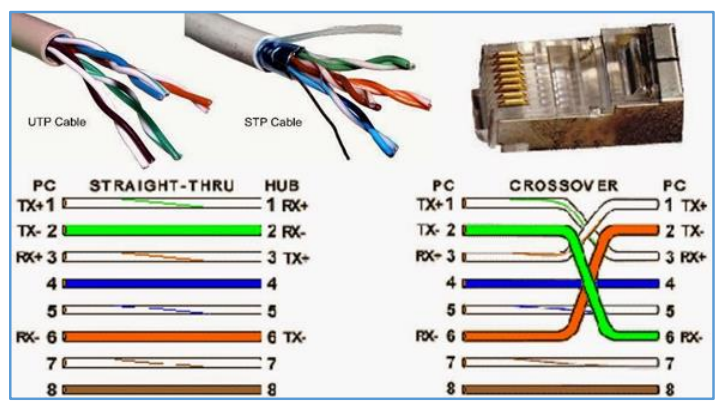

Gambar 4. Susunan kabel konektor catu daya ATX pada komputer

Power supply yang memiliki kabel power yang dihubungkan ke motherboard terpisah menjadi dua konektor power (P8 dan P9). ciri dari Power Supply jenis ini adalah saat mematikan komputer, tidak cukup hanya dengan menjalankan system shutdown, namun kita harus menekan tombol power setelah system shutdown berjalan. Power supply ini digunakan sampai pada era komputer pentium 2.
Power Supply ATX (Advanced Technology Extended ) Adalah power supply yang menggunakan 20/24 Pin kabel main power untuk motherboard. jenis ini adalah teknologi power supply terbaru saat ini. dimana sistem yang digunakan akan langsung menghentikan komputer hanya lewat system shutdown tanpa harus menekan tombol Power untuk mematikannya.

\section{METODE PENELITIAN}

Dalam penelitian ini menggunakan skala laboratorium komputer pada Universitas Muhammadiyah Metro. Adapun metode yang akan digunakan dalam penelitian ini yaitu dengan menggunakan metode eksperimental nyata (true experimental research). Dalam hal ini perangkat penelitian dibuat sesuai dengan ukuran turbin yang akan diamati. Metode ini dilaksanakan dengan melakukan pengujian untuk mengetahui pengaruh tegangan listrik pada catu daya komputer sebagai pengoptimalan arus listrik dengan DC. Tempat dan Waktu Penelitian penelitian ini dilaksanakan di Laboratorium Komputer Program D-III Manajemen Informatika Universitas Muhammadiyah Metro.

\section{Variabel Penelitian}

Variabel yang digunakan pada penelitian ini terdiri dari; variabel bebas, variabel terikat dan variabel terkontrol.

\section{Variabel Bebas}

Variabel bebas adalah variabel yang ditentukan nilainya sebelum dilakukan penelitian terdiri dari: nilainya sangat tergantung pada variabel bebas dan merupakan hasil dari pengamatan.

2. Variabel Pengawasan (kontrol)

Power AC/DC Adapter laptop merupakan Perangkat Notebook yang biasanya didukung oleh baterai isi ulang internal yang dibebankan menggunakan catu daya eksternal, dengan output tegangan DC biasanya di kisaran 7,2-14,8 volt. Power Adapter Laptop biasanya eksternal, dan terhubung ke laptop melalui kabel konektor 
AC. Power supply dapat mengisi baterai dan sebagai sumber daya laptop secara bersamaan, ketika baterai terisi penuh, laptop terus berjalan pada daya yang disediakan oleh power supply eksternal. Berat Power Adapter Laptop sekitar 400 gram dan ditambahkan ke keseluruhan berat notebook.

\section{Prosedur pengecekan catu daya pada komputer}

Banyak sekali kerusakan yang ditimbulkan oleh masalah kurangnya daya listrik, salah satunya adalah Power supply yang sering konslet atau lemah. Untuk melakukan pengecekan Power Supply sebaiknya hati-hati karena nanti kita akan berhubungan dengan arus listrik.

\section{Cara Cek PSU (Power Supply) Komputer}

2. Buka Power Supply atau keluarkan dari box CPU

3. Lepaskan seluruh kabel yang terhubung dengan motherboard, Harddisk, Fan dan CD player.

4. Siapkan kabel listrik panjangnya kurang lebih $3 \mathrm{~cm}$ kemudian kupas

5. Tancapkan kabel tersebut pada kabel yang terhubung langsung dengan motheboard. Cari yang warnanya hijau dan hitam.

Pasang kabel AC (listrik) powersupply dan hubungkan ke sumber arus listrik. Perhatikan kipas yang terdapat pada Power supply. Apabila kipasnya berputar dengan normal, maka kerusakan bukan pada Power Supply. mungkin pada komponen yang lain. Dan jika tidak berputar sama sekali berarti sumber masalahnya ada pada Power Supply tersebut. Kalau mati gunakan Power supply yang lain jika ada. Cek kembali apakah kipasnya berputar atau tidak. Kadangkadang kipas berputar sangat lemah sekali atau tidak normal, cobalah ganti yang lain atau beli yang baru. Jika kita menemukan masalah seperti ini, saya sarankan jangan didiamkan saja atau di jual. Bisa jadi matinya komputer itu karena berbagai sebab. Diantaranya :
1. Daya listrik yang kurang memadai

2. Motherboard kotor

3. Fan (kipas) proccesor penuh dengan debu

4. Kabel AC (listrik) yang terhubung dengan PSU (power supply) tidak tersambung sempurna.

Segeralah periksa bagian dalam

CPU kita, bersihkan lalu pasang lagi. Apabila masih tetap seperti semula (restart), baru periksa komponen-komponen komputer yang diduga sebagai penyebabnya. Pada postingan kali ini saya akan sedikit menjelaskan bagaimana mengatasi masalah yang berkaitan dengan poin 1 di atas. Banyak sekali kerusakan yang ditimbulkan oleh masalah kurangnya daya listrik, salah satunya adalah Power supply yang sering konslet atau lemah. Untuk melakukan pengecekan Power Supply sebaiknya hati-hati karena nanti kita akan berhubungan dengan arus listrik.

Tabel 1. Konsumsi listrik pada komponen komputer

\begin{tabular}{|c|l|}
\hline Tegangan & \multicolumn{1}{|c|}{$\begin{array}{c}\text { Alat-alat yang } \\
\text { menggunakan tegangan }\end{array}$} \\
\hline+3.3 volt & $\begin{array}{l}\text { Chipset, DIMM, Card PCI, } \\
\text { AGP, dan Chip lainnya. }\end{array}$ \\
\hline+5 Volt & $\begin{array}{l}\text { Disk drive logic, SIMM, } \\
\text { Card PCI, AGP, ISA } \\
\text { regualator tegangan, dan } \\
\text { Chip lainnya }\end{array}$ \\
\hline+12 volt & $\begin{array}{l}\text { Motor, Regulator tegangan } \\
\text { (output tinggi) }\end{array}$ \\
\hline
\end{tabular}

\section{Menginstalasi Power Supply}

Sebelum kita melakukan instalasi power supply, ada baiknya kita melakukan pengecekan power supply apakah dalam keadaan hidup atau mati, meskipun power supply tersebut baru. Hal yang perlu diperhatikan saat kita membeli power supply pastikan bahwa power supply dalam keadaan baik. Pengecekan dengan cara cepat adalah seperti langkah di bawah ini :

1. Siapkan main connector power supply 




Gambar 5. Main connector power supply

2. Colokkan ujung jumper satunya pada main connector kabel berwarna abu-abu

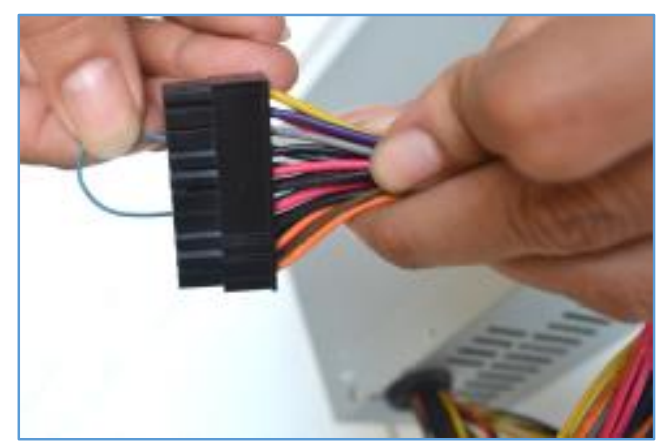

Gambar 7. colokkan

kabel jumper pada main connectorkabel berwarna abu-abu

3. Perhatikan fan/kipas pada power supply apakah hidup atau mati. Kalau fan/kipas power supply berputar berarti power supply dalam keadaan hidup, jika tidak berarti power supply bermasalah/mati

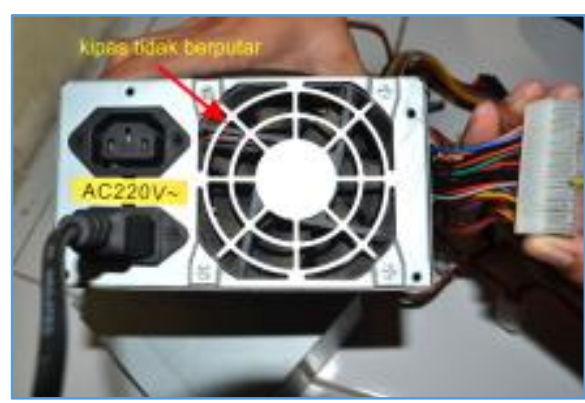

Gambar 7. Fan/kipas tidak berputar, berarti power supply bermasalah/mati



Gambar 8. Fan/kipas berputar, berarti power supplydalam keadaan hidup

Langkah menginstalasi power supply pada chase :

1. Buka kedua penutup samping chase,buka kedua penutup samping chase

2. Masukkan power supply pada dudukan chase. Perlu diperhatikan sesuai dengan keselamatan kerja, bahwa pemasangan power supply pada chase harus dalam keadaan chase berdiri. Banyak orang memasang power supply dengan posisi chase tidur. Pemasangan power supply dalam kondisi tidur akan menyulitkan saat kita memasang baut pengunci, bahkan lebih fatal lagi alur baut dan lubang baut pada chase bisa rusak pasang power supply pada dudukan chase sesuai dengan arah panah.

3. Pasang kedua baut power supply pada posisi paling atas terlebih dahulu. Kita memasang baut power supply paling atas terlebih dahulu dikarenakan, bagian bawah power supply sudah disangga oleh dudukan chase. Jika kita memasang dua baut posisi bawah maka berakibat bengkoknya baut dan rusaknya lubang baut chase posisi bawah, dikarenakan tumpuan power supply pada posisi bawah pasang 2 baut power supply posisi atas pada chase

\section{HASIL DAN PEMBAHASAN}

Dalam sistem pengubahan daya, terdapat empat jenis proses yang telah dikenal yaitu sistem pengubahan daya $\mathrm{AC}$ ke DC, DC ke DC, DC ke AC, dan AC ke 
AC. Masing masing sistem pengubahan memiliki aplikasi tersendiri, tetapi ada dua yang kita ketahui atau di kenal kemudian berkembang pesat dan luas yaitu sistem pengubahan AC ke DC (DC power supply)

Power Supply adalah perangkat keras yang berfungsi untuk menyuplai tegangan langsung kekomponen dalam casing yang membutuhkan tegangan, misalnya motherboard, hardisk, kipas, dll. Input power supply berupa arus bolak-balik (AC) sehingga power supply harus mengubah tegangan AC (arus bolak-balik) menjadi DC (arus searah).

dalam pengukuran tegangan power supply mesti di butuhkan ketereampilan dasar dalam menguasai alat ukur seperti avometer dan sebagainya adapun definisi powersupply itu sendiri antara lain :

1. Pengubahan Tegangan, berfungsi untuk mengubah tegangan listrik yang tersediadari jaringan distribusi transmisi listrik ke level yang diinginkan

2. Penyearah, sebagai pengubah arah tegangan atau voltase dari AC ke DC

3. Filter atau penyaring, bertugas sebagai pembersih gelombang keluaran dari riak (ripple) yang berasal dari proses penyearahan

4. Pengaturan (regulatorion), bertujuan untuk mengendalikan tegangan keluaran sehingga menjadi stabil walaupun terjadi variasi atau perubahan pada suhu, beban, maupun tegangan masukan dari jaringan transmisi listrik

Sebelum kita menuju mengukur tegangan power supply ada baiknya kita untuk memahami pengertian power supply itu sendiri:

\section{Mengukur tegangan power supply}

Dalam power supply ada tegangan yang berfungsi untuk mengatur masuk dan keluarnya arus listrik di dalam pc kita bila itu tidak ada mungkin pc kita bisa hangus powersupply juga memiliki tegangan yang bermacam-macam, kita mengukur tegangan power supply biasanya untuk mengetahui masik berfungsikah power supply tersebut atau tegangannya sudah drop alias sudah rusak, nah itulah kita gunakan alat pengukur namanya avo meter atau multitester. Power Supply adalah perangkat keras yang berfungsi untuk menyuplai tegangan langsung kekomponen__dalam casing yang membutuhkan tegangan, misalnya motherboard, hardisk, kipas, dll. Input_power supply berupa arus bolak-balik (AC) sehingga power supply harus mengubah tegangan AC menjadi DC (arus searah), karena hardware komputer hanya dapat beroperasi dengan arus DC. Power supply berupa kotak yang umumnya diletakan dibagian belakang atas casing.

\section{Cara Kerja Power Supply}

Sebuah DC Power Supply atau Adaptor pada dasarnya memiliki 4 bagian utama agar dapat menghasilkan arus DC yang stabil. Keempat bagian utama tersebut diantaranya adalah Transformer, Rectifier, Filter dan Voltage Regulator. Sebelum kita membahas lebih lanjut mengenai Prinsip Kerja DC Power Supply, sebaiknya kita mengetahui Blok-blok dasar yang membentuk sebuah DC Power Supply atau Pencatu daya. Ketika kita menekan tombol power pada casing, yang terjadi adalah langkah berikut. Power supply akan melakukan cek dan tes sebelum membiarkan sistem start. Jika tes telah sukses, power supply mengirim sinyal khusus pada motherboard, yang disebut power good. Prinsip Kerja DC Power Supply (Adaptor) - Arus Listrik yang kita gunakan dalam bentuk Arus Bolak-balik atau arus AC (Alternating Current). Hal ini dikarenakan pembangkitan dan pendistribusian arus Listrik melalui bentuk arus bolak-balik (AC) merupakan cara yang paling ekonomis dibandingkan dalam bentuk arus searah atau arus DC (Direct Current). Akan tetapi, peralatan elektronika yang kita gunakan sekarang ini sebagian besar membutuhkan arus DC dengan tegangan yang lebih rendah untuk pengoperasiannya. Oleh karena itu, hampir 
setiap peralatan Elektronika memiliki sebuah rangkaian yang berfungsi untuk melakukan konversi arus listrik dari arus AC menjadi arus DC dan juga untuk menyediakan tegangan yang sesuai dengan rangkaian Elektronika-nya. Rangkaian yang mengubah arus listrik AC menjadi DC ini disebut dengan DC Power Supply atau dalam bahasa Indonesia disebut dengan Catu daya DC. DC Power Supply atau Catu Daya ini juga sering dikenal dengan nama "Adaptor".

Sebelum kita membahas lebih lanjut mengenai Prinsip Kerja DC Power Supply, sebaiknya kita mengetahui Blok-blok dasar yang membentuk sebuah DC Power Supply atau Pencatu daya ini. Dibawah ini adalah Diagram Blok DC Power Supply (Adaptor) pada umumnya.



Gambar 9. Diagram Prinsip Kerja DC Power Supply (Adaptor)

\section{Jenis konektor kabel Power Supply}

Konektor 20/24 pin ATX Motherboard Konektor 4 pin peripheral power (untuk periferal seperti Hardisk, CD-ROM, Kipas)

Konektor $4 / 8$ pin $12 \mathrm{~V}$ (untuk motherboard server)

Konektor 6-pin PCIe (untuk kartu grafis jenis PCIe)

Konektor floppy (untuk floppydisk drive) Konektor SATA (untuk hardisk / optical drive berjenis sata)

\begin{tabular}{|c|c|c|c|c|c|}
\hline \multicolumn{6}{|c|}{$\begin{array}{l}\text { ATX CPU PSU Power Supply } \\
\text { Pin Assignment }\end{array}$} \\
\hline Pin & Signal & Color & Pin & Signal & Color \\
\hline \multirow{2}{*}{1} & \multirow{2}{*}{$+3.3 \mathrm{VDC}$} & \multirow{2}{*}{ Orange } & 11 & $+3.3 \mathrm{VDC}$ & Orange \\
\hline & & & [11] & [+3.3V Default Sense] & [Brown] \\
\hline 2 & $+3.3 \mathrm{VDC}$ & Orange & 12 & $-12 \mathrm{VDC}$ & Blue \\
\hline 3 & COM & Black & 13 & COM & Black \\
\hline 4 & $+5 \mathrm{VDC}$ & Red & 14 & PS ON & Green \\
\hline 5 & COM & Black & 15 & $\mathrm{COM}$ & Black \\
\hline 6 & $+5 \mathrm{VDC}$ & Red & 16 & COM & Black \\
\hline 7 & COM & Black & 17 & COM & Black \\
\hline 8 & PWR_OK & Gray & 18 & $-5 \mathrm{VDC}$ & White \\
\hline 9 & $+5 \mathrm{VDC}$ & Purple & 19 & $+5 \mathrm{VDC}$ & Red \\
\hline \begin{tabular}{|l|}
10 \\
\end{tabular} & $+12 \mathrm{VDC}$ & Yellow & 20 & $+5 \mathrm{VDC}$ & Red \\
\hline
\end{tabular}

Gambar 10. Pin pada Power Supply ATX $\mathrm{CPU}$

\section{Pengertian AVO Meter}

Avometer berasal dari kata "AVO" dan "meter". 'A' artinya ampere, untuk mengukur arus listrik. ' $\mathrm{V}$ ' artinya voltase, untuk mengukur voltase atau tegangan. ' $\mathrm{O}$ ' artinya ohm, untuk mengukur ohm atau hambatan. Terakhir, yaitu meter atau satuan dari ukuran. AVO Meter sering disebut dengan Multimeter atau Multitester. Secara umum, pengertian dari AVO meter adalah suatu alat untuk mengukur arus, tegangan, baik tegangan bolak-balik (AC) maupun tegangan searah (DC) dan hambatan listrik.

\section{Pengukuran Tegangan Power Supply Pada PC}

Power Supply Unit (PSU) memang termasuk komponen vital untuk kelangsungan sistem PC. Daya dari PSU yang berkurang atau berfluktuasi terlalu jauh dapat menyebabkan sistem selalu hang, booting, atau bahkan tidak bisa hidup sama sekali.

Periksa tegangan keluar dari PSU tersebut dengan bantuan Multimeter. Output dari power supply terbagi dalam 3 ukuran yaitu $12 \mathrm{~V}, 5 \mathrm{~V}$ dan $3.3 \mathrm{~V}$ untuk ATXataupun BTX. Kabel power terbagi ke dalam 4 kabel dengan warna Kuning (12 V), hitam,hitam,dan merah (5 V). Kabel ini bisa dikoneksikan ke Harddrive atau piranti optical storage (CD/DVD ROM Drive). Untuk mengukur output $5 \mathrm{~V}$, hubungkan multimeter pada kabel merah (+) dan hitam (-) dan baca hasil yang di dapat. Untuk output $12 \mathrm{~V}$ hubungkan kabel kuning (+) dan hitam (-) kemudian baca hasil yang didapat. Tegangan dari konektor power utama (20 pin ATX atau 24 pin BTX) juga dapat diukur untuk memastikan outputnya. Perhatikan saja titik plus dan minus (ground) untuk pengukuran tersebut. Hasil output yang didapat pada multimeter mungkin tidak persis atau mutlak 3.3/5/12 volt. Tegangan ini dapat bertoleransi turunnaik sekitar $5 \%$, misalnya 5.1 Volt, 11.8 Volt dan sebagainya. Namun bila jaraknya terlalu jauh, bisa dikatakan output dari PSU tersebut sudah tidak stabil dan dapat 
menyebabkan PC bermasalah, seperti cepat panas atau tidak stabil.

Toleransi Tegangan

Tegangan 3.3 Volt $\longrightarrow$ Batas Atas:3.4 Volt ...........Batas Bawah : 3.2 Volt

Tegangan 5 Volt $\longrightarrow$ Batas Atas: 5.2 Volt............Batas Bawah: 4.8 Volt

Tegangan 12 Volt $\longrightarrow$ Batas Atas: 12.5 Volt Batas Bawah : 11.5 Volt

Mengukur 3.3V:

1. Siap Multimeter dengan mengikuti instruksi di atas.

2. Masukan memimpin Merah ke dalam loop kawat seperti yang ditunjukkan.

3. Tegangan $3.3 \mathrm{~V}$ nyata akan muncul pada multimeter.

Mengukur 5V:

1. Siap Multimeter dengan mengikuti instruksi di atas.

2. Masukan memimpin Merah ke pin Merah dari konektor Molex.

3. Tegangan $5 \mathrm{~V}$ nyata akan muncul pada multimeter.

Mengukur 12V ini:

1. Siap Multimeter dengan mengikuti instruksi di atas.

2. Masukan memimpin Merah ke pin Kuning dari konektor Molex.

3. Tegangan $12 \mathrm{~V}$ nyata akan muncul pada multimeter.

Salah satu cara mengukur tegangan power supply yang bertegangan "0" kabel power putus atau bahkan saluran listriknya putus. Power Supply mengalami kerusakan, bisa drop (nyala sebentar terus mati) dan bisa mati total. Berikut Cara untuk mengecek power suply jenis ATX:

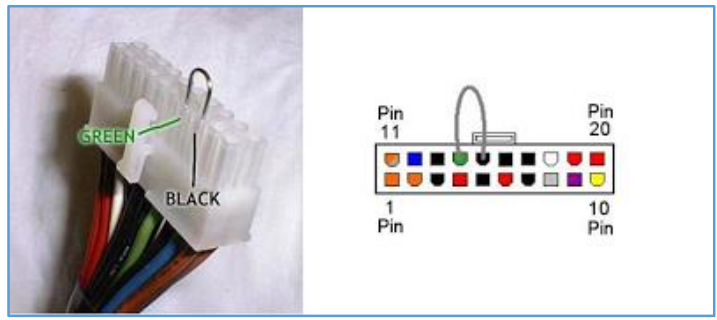

Gambar 11. Colokkan kabel powernya ke listrik.

Perhatikan kipas Power Supply, kalau berputar berarti Power Supply hidup. Akan tetapi Kipas Power Supply berputar belum tentu menandakan bahwa power supply itu bagus, karena ada banyak kasus power supply ATX itu mengalami arus/daya drop sehingga ketika disambungkan ke mainboard dan di bebani dengan harddisk, Komputer tetap tidak nyala / mati tapi kondisi fan masih berputar. Kondisi inilah yang dinamakan Power Supply Ngedrop. Berikut tanda power supply yang drop:

1. Komputer sering Hang sendiri.

2. USB port menjadi tidak berfungsi.

3. Kadang-kadang komputer restart sendiri.

4. Komputer nyala tampil di monitor tapi harddisk tidak terdeteksi di BIOS.

\section{KESIMPULAN}

Power supply adalah perangkat keras yang berfungsi untuk mengatur arus $\mathrm{AC}$ dan DC, atau arus masuk dan keluar menjadi arus searah, sedangkan AVO meter adalah alat pengukur tegangan perangkat keras seperti power supply dan sejenisnya. Prinsip Kerja DC Power Supply - merupakan sumber energi untuk sebuah komputer agar dapat beroperasi. Power supply mengubah arus dari AC 110 volt $60 \mathrm{~Hz}$ atau 220 volt $50 \mathrm{~Hz}$ menjadi $\mathrm{DC}+3,3$ volt, +5 volt dan +12 volt. Power Supply harus membawa suplai listrik DC yang baik dan stabil sehingga sistem dapat berjalan dengan baik. Alat yang berjalan pada tegangan yang disuplai oleh regulator tegangan onboard, sebagai contoh RIMM dan RIMM membutuhkan 2,5 volt 
sedangkan AGP AX dan card membutuhkan 1,5 volt, keduanya disuplai oleh regulator onboard dari motherboard. Selain menyuplai tenaga listrik, Power Supply dapat mencegah komputer untuk mulai dijalankan sampai tegangan Power Supply ada pada daerah yang telah ditentukan. Power Good merupakan tanda tes yang khusus yang dikirim ke motherboard sebagai sinyal aktif pada komputer, biasa ditandai dengan menyala warna hijau pada saat tombol power ditekan. Arus yang dikeluarkan oleh Power Supply merupakan arus searah (DC), daya yang dikeluarkan terdiri dari 200 watt, 250 watt, 300 watt, 350 watt, 400 watt hingga 600 watt. Komputer dengan prosessor Intel Pentium 4 keatas menggunakan daya sebesar 380 watt hingga 450 watt.

Dalam mengukur tegangan power supply perhatikan adanya kabel merah dan hitam pada avometer harus di colokkan pada connector power supply yang bertagangan power dan adanya arus listrik, dan jangan menggunakan power supply yang kurang dari watt tertentu jangan cepat menganbil keputusan dalam perbaikan power supply.

\section{DAFTAR PUSTAKA}

[1]. Ahmad Yani, (2006), Panduan Menjadi Teknisi

Komputer, Penerbit Kawan Pustaka, Jakarta.

[2]. Atang Gumawang., (2004), Merakit Komputer, Penerbit Informatika, Bandung.

[3]. Budi Astuti, (2013), Pengantar

Teknik Elektro, Penerbit Graha Ilmu, Jogjakarta.

[4]. Daryanto, (2011), Pengetahuan Teknik Elektronika, Bumi Aksara, Jakarta.

[5]. Melwin Syafrizal Daulay, (2007), Mengenal Harware - Sofware dan Pengolahan Instalasi Komputer, Penerbit Andi, Jogjakarta.

[6]. Saludin Muis, (2014), Perancangan Power Supply SwitchMode, Penerbit Graha Ilmu, Jogjakarta.

[7]. S Sudarmaji., (2013), MANFAAT SERTA PEMAHAMAN MANAJEMEN PERANGKAT KERAS (HARDWERE) DALAM SISTEM KERJA PERSONAL COMPUTER (PC). Mikrotik 1(1) 